\title{
Specialist 'restoration mortars' for stone elements: a comparison of the physical properties of two stone repair materials
}

\author{
Clare Torney $^{1 * \dagger}$, Alan M Forster ${ }^{2 \dagger}$ and Ewan M Szadurski ${ }^{2+}$
}

\begin{abstract}
Background: The perceived increasing use of 'restoration mortars' for the conservation of historic masonry is often viewed as controversial due to the long-standing contention associated with 'plastic' repairs in the heritage sector. Almost innumerable traditionally built sandstone structures exist worldwide and the wide scale use of restoration mortars for their repair is evident on a national and international level. Use of largely incompatible, impermeable and/or highly cementitious materials in the past is the cause of many problems, particularly associated with moisture entrapment. These issues, that continue several decades after a material's use, raise the question of whether similar problems are likely to arise in the future due to the use of restoration mortars.

Results: The chemical and physical characteristics of two restoration mortars are determined by laboratory testing. This work revealed significant differences in the physical properties of two restoration mortar materials, but also between these and the physical properties of two natural sandstones. Material characterisation reveals differences between the composition of the binders and aggregates in the two restoration mortars tested. Significant differences in their strength and water diffusion properties were noted.

Conclusions: The results provide an indication of material performance and a platform for objective decision-making on the suitability and specification of these materials. This work is of particular importance in the heritage sector, but its applicability is not limited to historic buildings. Comparison of the materials properties presented in this paper with the characteristics of representative sandstone substrates can give an indication of material compatibility. This research is aimed at stimulating further testing into the interactions of these materials within the context of historic masonry substrates.
\end{abstract}

\section{Background \\ Masonry repair}

Deterioration of stone masonry is a worldwide problem, which can be addressed by replacement of entire stone units, by consolidating the delaminated surfaces or by plastic repair [1]. The nature of substrate materials and their state of conservation offers almost unlimited permutations in specification and technical repair solutions. Plastic repair using a restoration mortar is one popular method used for the treatment of a number of different building elements [2]; the word 'plastic' denotes the

\footnotetext{
*Correspondence: Clare.Torney@scotland.gsi.gov.uk

${ }^{\dagger}$ Equal contributors

'Historic Scotland Conservation Directorate, 7 South Gyle Crescent, Edinburgh, UK

Full list of author information is available at the end of the article
}

plasticity of the fresh mortar rather than any specific composition [3]. Used within a philosophical framework of repair (Figure 1) this method can, in the short-term, provide a lower cost alternative [1]. The reinstatement of natural stone is often associated with the removal of potentially large quantities of existing masonry and is therefore often viewed as being overly intrusive $[1,2,4]$. Partly as a result of this, 'plastic' repairs appear to have increased in popularity and prevalence since the 1960's $[1,2]$. However, the damage caused to host masonry by using inappropriate repair materials is well documented, and is perhaps most well known in cases of repair using Portland Cement based materials [5-7]. Less well known is the fact that damage can be caused by other materials of low permeability, including excessively strong (i.e. eminently hydraulic) lime mortars, which may result
(C) Chemistry Central

(C) 2014 Torney et al.; licensee Chemistry Central Ltd. This is an open access article distributed under the terms of the Creative Commons Attribution License (http://creativecommons.org/licenses/by/2.0), which permits unrestricted use, distribution, and reproduction in any medium, provided the original work is properly cited. 


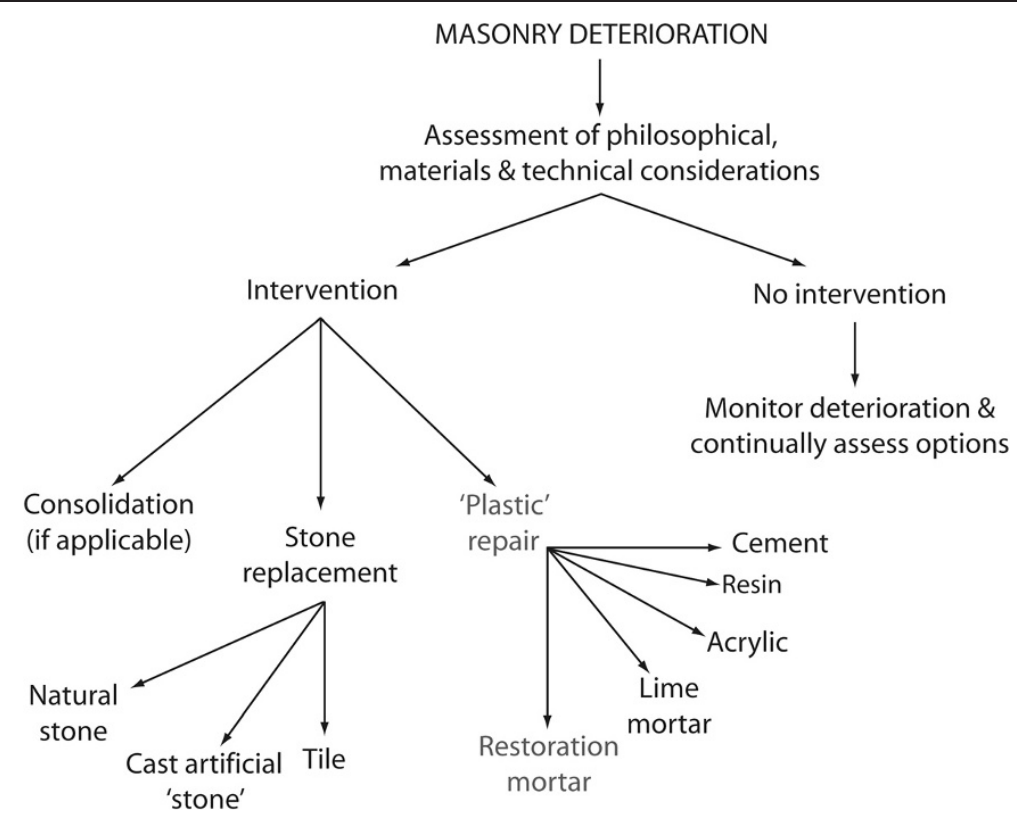

Figure 1 Remedial action options for cases of masonry deterioration. Based on current literature [1,3].

in entrapment of moisture. This can lead to accelerated deterioration of masonry due to mechanisms such as freeze-thaw cycling and salt sub-florescence [6,8-11]. Furthermore, the current and future predicted alteration in rainfall patterns associated with climate change [12] are likely to result in escalation of building performance stress issues associated with moisture management.

Much research has been undertaken [13] upon the physical, chemical and microstructural properties of Portland Cement-based mortars and renders. Accordingly, an increasing understanding of the associated failure-inducing mechanisms of such products, used in-conjunction with porous building materials is developing (e.g. $[5,7,14])$. This knowledge and experience has led to the reintroduction of lime (Table 1) as a repair material for building conservation work.

Mikos et al.'s [15] work on restoration of natural stone surfaces highlights primary physical testing methodologies and visual aesthetic considerations (including colour matching and surface finish). At the heart of Mikos et al.'s [15] work is the importance of determining

Table 1 Compressive strength ranges for natural hydraulic lime mortar samples prepared in accordance with the current British Standard (BSI, 2010)

\begin{tabular}{lll}
\hline Classification & $\begin{array}{l}\text { 28 day compressive } \\
\text { strength }(\mathbf{M P a})\end{array}$ & Traditional terminology* \\
\hline NHL 2 & $\geq 2$ to $\leq 7$ & Feebly hydraulic \\
NHL 3.5 & $\geq 3.5$ to $\leq 10$ & Moderately hydraulic \\
NHL 5 & $\geq 5$ to $\leq 15$ & Eminently hydraulic \\
\hline
\end{tabular}

* Traditional terminology only loosely relates to modern classification. In reality, modern limes are much stronger than those produced historically. compatibility to ensure the minimisation of harm to host substrates. The established key characteristics find broad agreement with various authors working in this area [15-17]. The assessment of these characteristics are not necessarily absolute values, but reflect useful, measureable performance trends [15] and therefore must also be seen within a context of the substrate and other practical on site variables. Mikos et al. [15] indicates amongst others, some essential requirements and characteristics for consideration, including; mineralogical and chemical composition, the understanding of the development of physical characteristics (including hygrothermal parameters, capillary water absorption \& water vapour permeability), curing regime and application factors.

Mikos et al. [15] continues to emphasise the importance of involving expert assessment in the determination of, and translation of practical recommendations into tangible specification for repair works to natural stone.

As aforementioned, the suitability of a material for masonry repair is ultimately dependent upon its compatibility with the host masonry. Schueremans et al. [17] define compatibility as 'using materials that do not have negative consequences on the authentic materials'. Whilst compatibility could be viewed as a somewhat nebulous term, work by Rodrigues and Grossi [16] emphasises that it can be objectified by using 'compatibility indicators'. Compatibility indicators are multifaceted in nature, can be used in several dimensions, and when utilised in their final form enable tangible quantification of a specific aspect of performance to be determined [16]. Whilst not all parameters have been measured in this work, the research collectively fills gaps in knowledge to better enable utilisation of critical 
compatibility models and evaluation tools. The parameters selected for this work are ostensibly 'major branch' or 'first order' critical indicators [16], such as water vapour permeability, sorptivity and compressive strength etc.

It is understood that the selection of a large range of compatibility indicators is also no guarantee of 'good' assessment and Rodrigues and Grossi [16] have suggested that an overly 'data heavy' approach can detract from a meaningful evaluation due to increased complexity. It is recognised that difficulties exist in the development of working methodologies due to large numbers of potential compatibility indicators and this work finds commonality with many of the parameters for mortar and applied masonry established by Rodrigues and Grossi [16], and Schueremans et al. [17], including, investigating mineralogical, chemical, mechanical and physical factors. Schueremans et al.'s [17] 3 stage methodological approach for the determination of compatibility utilised pre-investigation, materials specification and post application re-evaluation of performance. The evaluation of predicted and actual performance could be argued to be a true measurement of ultimate compatibility and obviation of fabric harm. This project was borne out of extensive evaluation of site based application of repair materials [2]. Therefore the reality of wide scale repair material use underpins the laboratory tests adopted.

Lime and cement are both common binders utilised in plastic repair products. They compose the base of the mortar that forms the bonding 'matrix' between aggregate grains [18] and may be used individually or in combination, as a 'hybrid' mix. Both lime and cement are, or have been, frequently used for masonry repair in Scotland, with varying degrees of success [2]. To a lesser degree, materials may be based on epoxy resin or acrylic resin binders, however these have not been identified as common repair materials for buildings [2]. Epoxy resin and acrylic resin binders are more likely to be used in the conservation of objects, and are outside the scope of this work.

Amongst other factors it is the combination of the relatively high vapour permeability (i.e. the material's ability to facilitate movement of moisture in the vapour phase) of lime and its transport characteristics of liquid water [18] that puts it much higher up this compatibility ranking than Portland cement. In addition to these factors, porosity, water absorption and response to repetitive wetting and drying cycles and flexural response are considered key 'second order' factors in the understanding of a plastic repair material's compatibility and performance [3]. Consideration of broader issues are also essential such as; aesthetic, technical and structural factors and these need to be applied to the selection process for repair mortars (e.g. repointing mortar, renders, plasters) [19-22].

Whilst performance advantages of lime are evident [7], the practical use of the material is somewhat relatively demanding with specialist skills required to ensure satisfactory execution. In light of this, combined with the aforementioned Portland cement performance deficiencies, a new generation of potentially easier to use products, specifically for masonry repair, has been developed. These are collectively known as 'restoration mortars'. Restoration mortars are formulated, dry packaged materials with standardised binder to aggregate ratios that are theoretically optimised during manufacture. These predetermined constituents reduce the risk of failure associated with drying shrinkage and inaccurate batching measurements [2]. Many of these products offer a range of benefits to the user including ease of preparation and application, and claim positive performance characteristics such as high 'breathability'. Breathability is a somewhat nebulous term and although manufacturers do not necessarily quantify what this means, it is defined by Forster [23] as 'a measure of a combination of moisture transfer mechanisms' including water vapour permeability and water permeability. However, these proprietary materials, of which there are many commercially available, can vary significantly from manufacturer to manufacturer (based on available technical and health and safety literature). Common variations in formulated mortars included binder, aggregate components and additives. Clearly these differences would be expected to be reflected in the different physical characteristics.

Established guidelines for the use of appropriate materials as a means of surface repair of natural stone [24] explicitly state that 'special mortars', which presumably includes restoration mortars, can be used for 'repairs to localized areas of damage'. Similar views are expressed in relation to plastic repairs in general by Ashurst and Ashurst [3], Glasgow Conservation Trust [25] and Historic Scotland [26]. Despite the often cautious viewpoints and recommendations on restricted use of plastic repair materials in these works, problems of over-zealous use of materials still occur. This is evident from the evaluation of repairs to large numbers of sandstone masonry tenement blocks in the central belt of Scotland [2]. The often extensive deterioration of building stone further afield (e.g. Europe [27], Australia [10,28] and the United States [29]) presents opportunity for the use of restoration mortars on a much wider scale, highlighting the international impact of this work.

Although mass masonry sandstone buildings represent much of the pre-1919 building stock in Scotland, no independent research on the short or long-term effects of using restoration mortars on Scottish sandstone buildings has been carried out. European studies into formulated mortars have focused on repair to limestone [30] or mortar for other functions (e.g. repointing and bedding [31]). Furthermore, restoration mortars claim to be suitable for use on a range of substrates, with some covering 
brickwork and concrete block work as well as a number of stone types. It is unclear as to whether or not this universal approach is appropriate, especially given the exceptionally diverse nature of building stone types (e.g. [32]) and their equally diverse physical properties [33], not only in Scotland but also further afield. The compatibility, in terms of properties such as strength and vapour permeability, of restoration mortars within the important context of stonemasonry substrates has not been tested. This work is therefore important to allay or confirm fears of repeating the previous failures associated primarily with low permeability surface repair materials. The aim of the present research is to provide a better understanding of the physical properties of two commercially available restoration mortars. It is acknowledged that studying a wide scope of properties, including thermal and hygric expansion, adhesive (bond) strength and weathering characteristics (e.g. [20]), of the repair materials would be beneficial in understanding the materials holistic performance $[16,17]$. Additionally, the study of flexural response of the stone types is generally an important feature of compatibility but in this case was considerably lower than any of the restoration mortars and was therefore not integrated into this study. The present work therefore focuses on a smaller range of properties that are considered by the authors to give an immediate indication of a material's compatibility potential. It must be emphasised that these compatibility indicators also form an integral component of broader evaluative protocols established by Rodrigues and Grossi [16]. Additionally, operative focused on-site suitability factors have been used to substantiate further testing as required including carbonation rates, and workability. The results can then be compared to the physical properties of any stone (or other potential substrate) to assess the compatibility of the materials. This work aims to contribute to platforms [16] for making objective decisions on the compatibility and suitability of specifications of materials for different substrates. This is a critical requirement in the conservation sector and repair of many traditionally built structures.

\section{Materials and methods}

\section{Materials: restoration mortars}

Two restoration mortars were selected for analysis: Lithomex (Chaux et Enduits St. Astier (CESA), France) and Conserv (Stone Tech (Cleveland) UK). The former has been highlighted in another study [2] as a popular stone repair material in Scotland hence its inclusion in this study, and the latter was selected based on its diffusivity and therefore availability within the UK via established supply chain and pronounced merchant outlets. Both repair products can be altered to visually match different stone types; in the case of Lithomex this is achieved by adding pigment, and in Conserv by using aggregates of differing colours and textures. The materials chosen for analysis in the present study represent the basic mixes in their standard form, i.e. the materials have not been formulated with any additional pigments, aggregates or 'tooled' to achieved an optional surface finish.

Lithomex is a formulated, anhydrous mortar designed for the repair or simulation of brick or stone masonry and is a blend of natural hydraulic lime and hydraulic binder, filler, lightweight aggregate and additive' [34]. Concentrations (expressed as percentage of binder) stated by the manufacturer are as follows: calcium hydroxide $\leq 20 \%$; hydraulic binder (Portland cement) $\leq 20 \%$; filler (vermiculite) $\leq 5 \%$. Based on this information, the strength gain of Lithomex during setting and hardening is expected to proceed via both hydration and carbonation. This limecement hybrid adopts a 'mix and go' approach and comes with a strict set of guidelines for its preparation and application. The quantity of water added to the dry material depends on the stiffness required, as determined by the repair type. The manufacturer advises (on product packaging) $4.5-5.5 \mathrm{~L}$ of water per $25 \mathrm{Kg}$ of dry material. The material should be mixed with water for between 3 and 5 minutes prior to use. According to manufacturers data [35] this should result in a compressive strength value of $7.25 \mathrm{MPa}$ at 28 days.

Conserv 'natural stone repair mortar' is intended for use on sandstone and limestone substrates. The product can be supplied at different levels of hydraulicity (Table 1) (using NHL 2, NHL 3.5 or NHL 5 binder) to suit different masonry substrates and site conditions. Communication with the manufacturer indicated that unless otherwise specified by the client, an NHL 3.5 binder with crushed Stainton sandstone aggregate is the product supplied; this was the mix chosen for the present research. Based on this composition, Conserv is likely to cure via both carbonation and hydration reactions. Carbonation in an NHL 3.5 mortar is likely to account for $20-25 \%$ of strength development, and hydration for the remaining $75-80 \%$, depending on the exact composition of the lime [36]. In contrast to Lithomex, the absence of cement means that hydraulic development in Conserv is expected to be a relatively slow process, as it proceeds via the hydration of $\beta$-belite.

Conserv stone repair mortar is supplied in tubs and offers a 'ready to mix, just add water' convenience. However, the lime is bagged separately within the tub to prevent deterioration of the binder associated with hydration and carbonation due to absorption of moisture and carbon dioxide from the humid air, or damp sand [18]. Dry mixing is required before the addition of water to ensure a homogeneous mix. Although step by step instructions on material application and aftercare are provided, there is no information on the water requirements or optimum mix time of the mortar. Additionally, no technical data relating to strength, water absorption or vapour permeability was 
provided by the manufacturer at the time of purchase in 2012.

\section{Sample preparation}

Samples of the two restoration mortars underwent different mixing regimes (water contents and mix times). Although such variation is not usually adopted in studies of material properties, it was necessary in this case to ensure that the products were prepared in accordance with the corresponding manufacturer's guidelines.

Lithomex was batched (by weight) in the ratio 1 part water to 5 parts powder $(20 \mathrm{~mL}$ water per $100 \mathrm{~g}$ powder, representing the mid-point values of the manufacturers recommended water content range) and mixed mechanically for 4 minutes, as prescribed by the manufacturer's guidelines. Mixing was carried out in a bench-top paddle mixer, the sides of which were scrapped after 2 minutes to ensure all dry powder was incorporated into the mix. Consistency was determined using a flow table, in accordance with British Standards [37], and was found to be $152 \mathrm{~mm}$.

Conserv stone repair mortar was supplied at a binder to aggregate ratio of 1:7.5 (by weight). The two components were mixed dry using a paddle mixer until the binder was well dispersed amongst the sand, then water was added in the ratio of 1 part water to 4 parts dry mix (by weight). The material was mixed for 20 minutes; the sides of the mixer were scrapped after 10 minutes, to ensure thorough mixing, the material was left for 30 minutes before remixing for a final 10 minutes. Water content and mix time were based on a number of trials during which mortar workability was assessed for adhesion to a sandstone substrate. The final, workable, mortar had a flow table value of $135 \mathrm{~mm}$. Work on rheological properties of formulated mortars has not been undertaken by other researchers to date. Work on flow characteristics of natural hydraulic limes have been undertaken by Allen et al. [18] but the water ratios are significantly different from those required for formulated materials.

Specimens of both materials were prepared as $40 \mathrm{~mm} \times$ $40 \mathrm{~mm} \times 160 \mathrm{~mm}$ rectangular prisms in single-use polystyrene 3-gang disposable prism moulds with lids. Disposable moulds were used as an alternative to steel moulds as they eliminate the need for releasing agent and any associated uncertainties regarding the interaction of the two surfaces. With the aim of producing samples consistent with material usage on site, the mortars were packed into the moulds using a trowel but were not subjected to vibration or jolting.

While enclosed in moulds, samples remained in a damp environment, creating favorable conditions for the formation of early stage hydration products. Lithomex samples were kept in moulds for 24 hours and Conserv samples for 72 hours. Lithomex manufacturer's guidance does not indicate the need to keep the material damp; this may indicate the presence of water retaining additives, although, if present, these are not declared in the manufacturer's data. However, hydraulic lime mortars are required to be kept damp to ensure the progression of hydration reactions $[7,18]$ and this was the approach taken with the Conserv samples. When removed from the moulds both Lithomex and Conserv mortar prisms were lightly rubbed with a tungsten carbide abrasive pad. This process was undertaken to open the pore structure and remove laitance that is understood to inhibit carbonation in lime mortars [38]. All specimens were cured in a stable laboratory environment of nominally $55 \%$ relative humidity and $20^{\circ} \mathrm{C}$ until the time of testing.

Specimens for vapour permeability testing were $10 \mathrm{~mm}$ thick cast in cylindrical polystyrene moulds of $75 \mathrm{~mm}$ diameter. After demoulding, specimens were lightly rubbed with an abrasive pad to remove laitance and then cured in the same conditions as rectangular prisms.

Additionally, two sandstones (Stanton Moor and Locharbriggs, UK) were investigated to give an indication of potential substrate properties. Their different physical properties $[39,40]$ are representative of the wide range of sandstone types used both in construction historically, and currently [33] for repair work to historic masonry structures.

\section{Testing methods}

Mortar prisms were oven dried at $105^{\circ} \mathrm{C}$ for 12 hours to attain a constant weight prior to testing and in order to prevent the continuation of hydraulic reactions. Compressive strength, carbonation and sorptivity were measured at seven, 28, 56, 91 and 182 days. The impact of oven drying on compressive strength of samples was determined prior to testing. Lithomex and Conserv samples experienced an increase in compressive strength of $4.2 \%$ and $5.7 \%$ respectively. In each case a minimum of three samples of each material were tested. Each prism was snapped in half, one half was tested using Phenolphthalein indicator, to give an indication of the depth of carbonation, and subsequently used for sorptivity tests, while the other was used for compressive strength testing.

\section{Material characterisation}

Grading of material by sieve analysis was carried out in accordance with British Standards [41]. As Lithomex is supplied as a formulated mortar, sieve analysis incorporated aggregate, binder and fillers, for Conserv, aggregate was analysed in isolation. Both unmixed materials were characterised by sieve analysis and powder X-Ray diffraction (XRD). XRD was carried out on Lithomex passed through a $63 \mu \mathrm{m}$ mesh (this removed most but not all aggregate) and Conserv binder. XRD samples were analysed on a Thermo ARL X'TRA Diffractometer with a 2 Theta range of $5^{\circ}-70^{\circ}$ at a rate of $1 \%$ min. 


\section{Compressive strength}

Compressive strength was determined on $40 \mathrm{~mm}$ cubes, cut from one half of a snapped prism. Conserv stone repair mortar was tested on a Lloyds M5K universal testing machine with a $5 \mathrm{kN}$ load cell applied at a rate of $0.5 \mathrm{~mm} / \mathrm{min}$. Lithomex proved too strong for this, so specimens were instead tested on an Avery-Denison compressive test machine with a load cell of $3000 \mathrm{kN}$ applied at a rate of $10 \mathrm{kN} / \mathrm{min}$. Both machines had been calibrated before use.

\section{Sorptivity}

Moisture handling characteristics were determined utilising the 'Sharp Front' theory of unsaturated moisture flow. This provides information relating to the sorptivity of the material which is defined as the tendency of a material to absorb and transmit water and other liquids by capillarity' [42]. Sorptivity is a property which is rigorously defined by the fundamental hydraulic properties and is a function of the diffusivity $\mathrm{D}$, the conductivity $\mathrm{K}$ and the potential $\Psi$ of a material [42]. Hall \& Hoff [42] indicate that the sorptivity of material can be used to aid specification and acts as a determinant of longer term durability. The sorptivity of the samples for this work have been calculated using the direct gravitational method. The samples are sealed on all sides with Araldite ${ }^{\circ}$ resin, except for the $40 \mathrm{~mm} \times 40 \mathrm{~mm}$ surfaces which were left uncoated. Specimens are first dried, weighed and then placed elevated off the base of a water tank by nonabsorbent supporting rods to allow water to contact the unsealed cast surface of the specimen only. Samples were then removed and weighed at intervals of one, four, nine, $16,25,36,49$ and 64 minutes. For the Sorptivity (S) to be determined a minimum of 5 points are required on a straight line gradient of the graph of mass gain by surface area $(\Delta \mathrm{w} / \mathrm{g})$ against $\sqrt{\text { time }}(\sqrt{ } \mathrm{t})[42]$. The sorptivity value is given in units of $\mathrm{mm}$ min-1/2. If measured points do not fit on a straight line the sorptivity cannot be calculated. This technique is similar to BS EN 15801 [43] in so much as a straight line fit is required but the samples are not sealed and the units differ. In BS EN 15801 [43] the units are in $\mathrm{kg} /\left(\mathrm{m}^{2} 1 / 2 \mathrm{sec}\right)$ [42] the sorptivity method it is $\mathrm{mm}$ min-1/2. Having the sides unsealed as in BS EN 15801 [43] can cause deviation in results as the displaced air by the uptake of water can escape laterally as well as vertically thus giving an increase in the sorptivity value [42]. The sharp front method developed by Hall \& Hoff [42] enhances accuracy and predicted moisture flow in porous materials over and above BS15801.[43].

\section{Vapour permeability}

Vapour permeability was determined by the wet-cup method, following the same principles as the British Standard [44]. Specimens were placed on the mouth of a cup containing a saturated potassium nitrate solution and sealed in place using silicone sealant. The distance between the sample and the desiccant was $10 \mathrm{~mm}$. Sample cups were placed in a TAS Series 3 MTCL environmental test chamber with constant conditions of $20^{\circ} \mathrm{C}$ and $65 \%$ $\mathrm{RH}$. Weight was recorded at the beginning of the experiment and periodically over a period of 21 days during which a constant weight loss rate was observed in all samples. Vapour permeability, expressed as permeance $(\Lambda)$, was calculated using equation 1 . The units are expressed in $\mathrm{kg} \mathrm{m}^{2} \mathrm{~s} \mathrm{~Pa}[44]$ :

$$
\Lambda=1 /(\mathrm{A} \Delta \mathrm{p} / \Delta \mathrm{G} / \Delta \mathrm{t})-\mathrm{R}_{\mathrm{A}}
$$

Where A is the area of the open mouth of the test cup; $\Delta \mathrm{p}$ is the difference in water vapour pressure; $\Delta \mathrm{G} / \Delta \mathrm{t}$ is the weight loss from the test cup; and $R_{A}$ is the water vapour resistance of the air gap between the potassium nitrate solution $\left(\mathrm{KNO}_{3}\right.$ solution $=95 \% \mathrm{RH}$ partial driving pressure $)$ and the test specimen.

\section{Results and discussion \\ Material characterisation}

Lithomex is fine grained with only $7 \%$ of material retained on a $0.5 \mathrm{~mm}$ sieve and the majority of material between $250 \mu \mathrm{m}$ and $125 \mu \mathrm{m}$ (Figure 2a). The largest grains were evaluated using a stereomicroscope and were identified as quartz and vermiculite. Calcite, talc, alite and $\beta$-belite were identified using XRD (Figure 3a). Calcite may represent unburnt limestone in the lime binder. Talc is a commonly used filler [45], and the calcium silicates, alite and $\beta$-belite are components of the cement and hydraulic lime binders. The absence of brownmillerite indicates that white cement, manufactured using components low in iron, is present [46]. As a lime-based material Lithomex binder would be expected to contain portlandite. This component $(\leq 20 \%([35]))$ was detected in 56 day Lithomex samples, but not in anhydrous Lithomex. The absence of portlandite in the anhydrous Lithomex may be associated with the qualitative nature of XRD technique.

Conserv aggregate has a substantially smaller particle size than Lithomex and this was evaluated again using a stereo microscope. The composition was found to consist primarily of quartz grains (Figure $2 \mathrm{~b}$ ) with a void ratio of $44 \%$ (determined using the method outlined by Gibbons [7]). XRD of the binder indicates the presence of calcite, as unburnt limestone; portlandite; and $\beta$-belite. The latter, combined with the absence of alite and other silicates, indicates that this is a hydraulic lime with no additions of cement (Figure $3 b)$.

\section{Carbonation}

Figure 4 illustrates the progress of carbonation in the two mortars. The lack of any complete carbonation in 
(a)

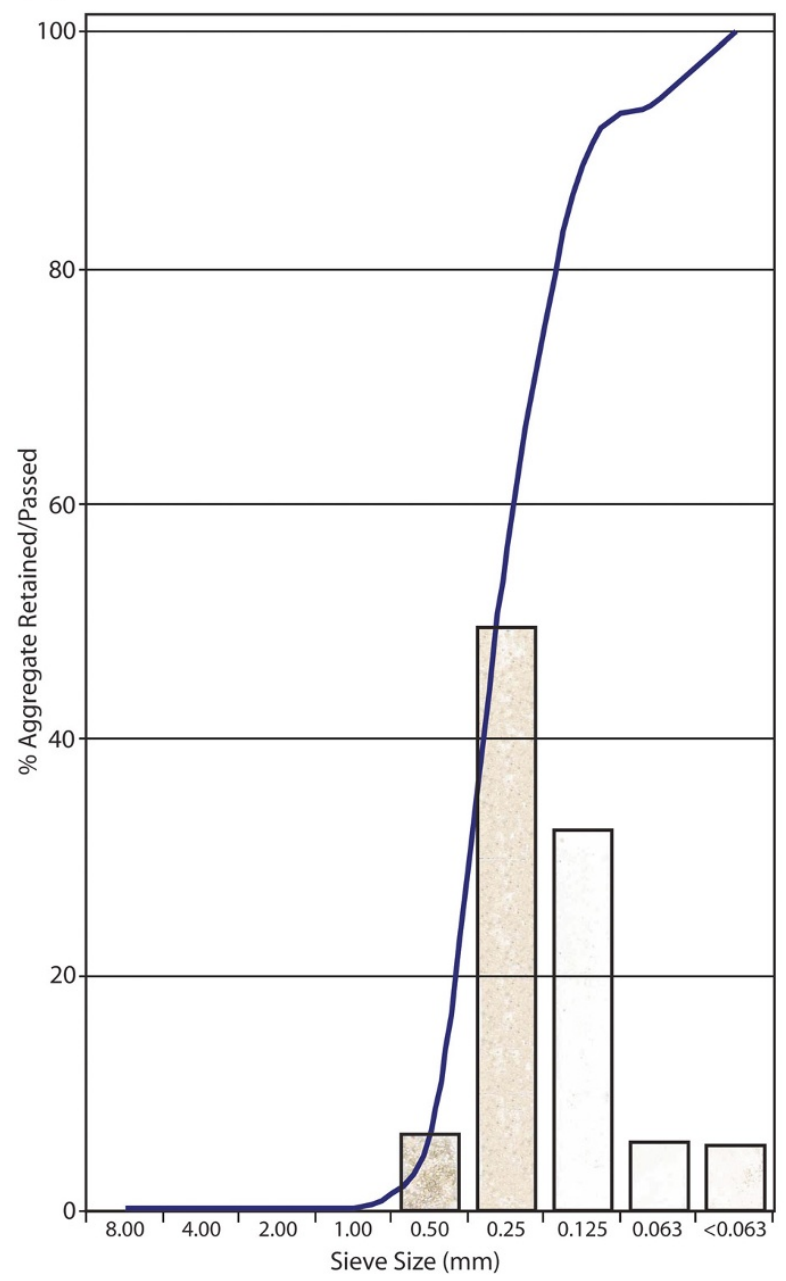

(b)

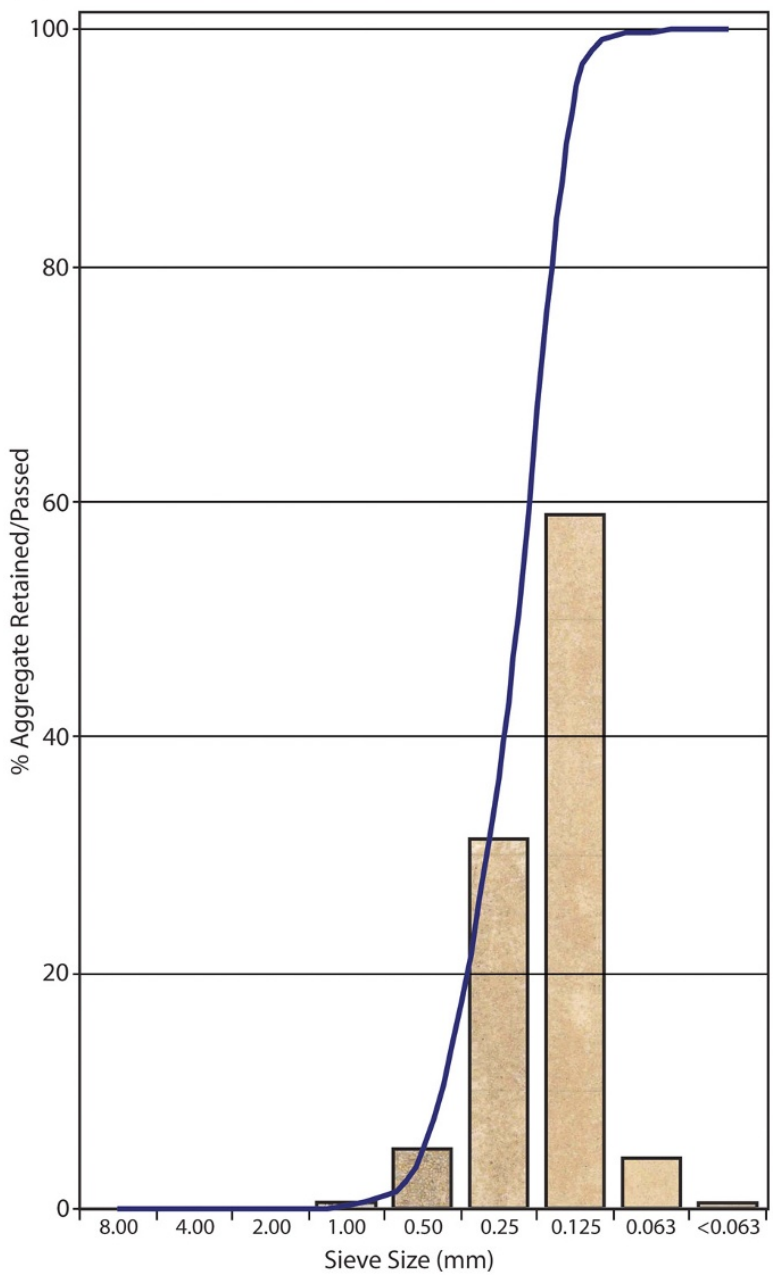

Figure 2 Particle size distributions of materials as supplied. (a) Lithomex, showing aggregate, binder and filler, (b) Conserv, showing aggregate only. Grading bar charts show percentage of aggregate retained; superimposed 'S' curves indicate cumulative \% aggregate retained in each sieve fraction.

Conserv (which would be marked by a colour change upon Phenolphthalein application) at seven days is the result of its extended setting time within covered moulds, during which the samples remained saturated. After this point Lithomex and Conserv exhibit similar carbonation patterns (Figure 4). The rate of carbonation decelerates between 28 and 56 days, more so in Conserv than Lithomex. After this an increase was noted for the remainder of the test period. Both mortars reached full carbonation by 182 days, suggesting that carbonation in deeper layers would reach a minimum of $20 \mathrm{~mm}$ by this time.

\section{Compressive strength}

Hydration of hydraulic components from both the hydraulic lime and cement binders results in the production of C-S-H. Hydration of cement clinker components, such as alite $\left(C_{3} S\right)$, occurs significantly more rapidly than hydraulic components associated with lime (i.e. $\beta$-belite) [36]. The hydration of alite is therefore responsible for early strength gain in Portland cement materials. Carbonation of calcium hydroxide in the mixed material, combined with the continuation of $\beta$-belite hydration, will account for the longer term strength development in hydraulic limes [36,47].

The compressive strength of the two restoration mortars is significantly different (Table 2). Lithomex samples rapidly developed strength in the early stages of curing, the rate of which slows considerably after 7 days. This pattern meets expectations based on XRD results: rapid strength gain in Lithomex can be explained by the early hydration of alite to produce C-S-H. The decrease in compressive strength of Lithomex from 28 to 56 days could be a reflection of pore size changes associated with carbonation (as is evident in air limes [48]), made apparent due to 


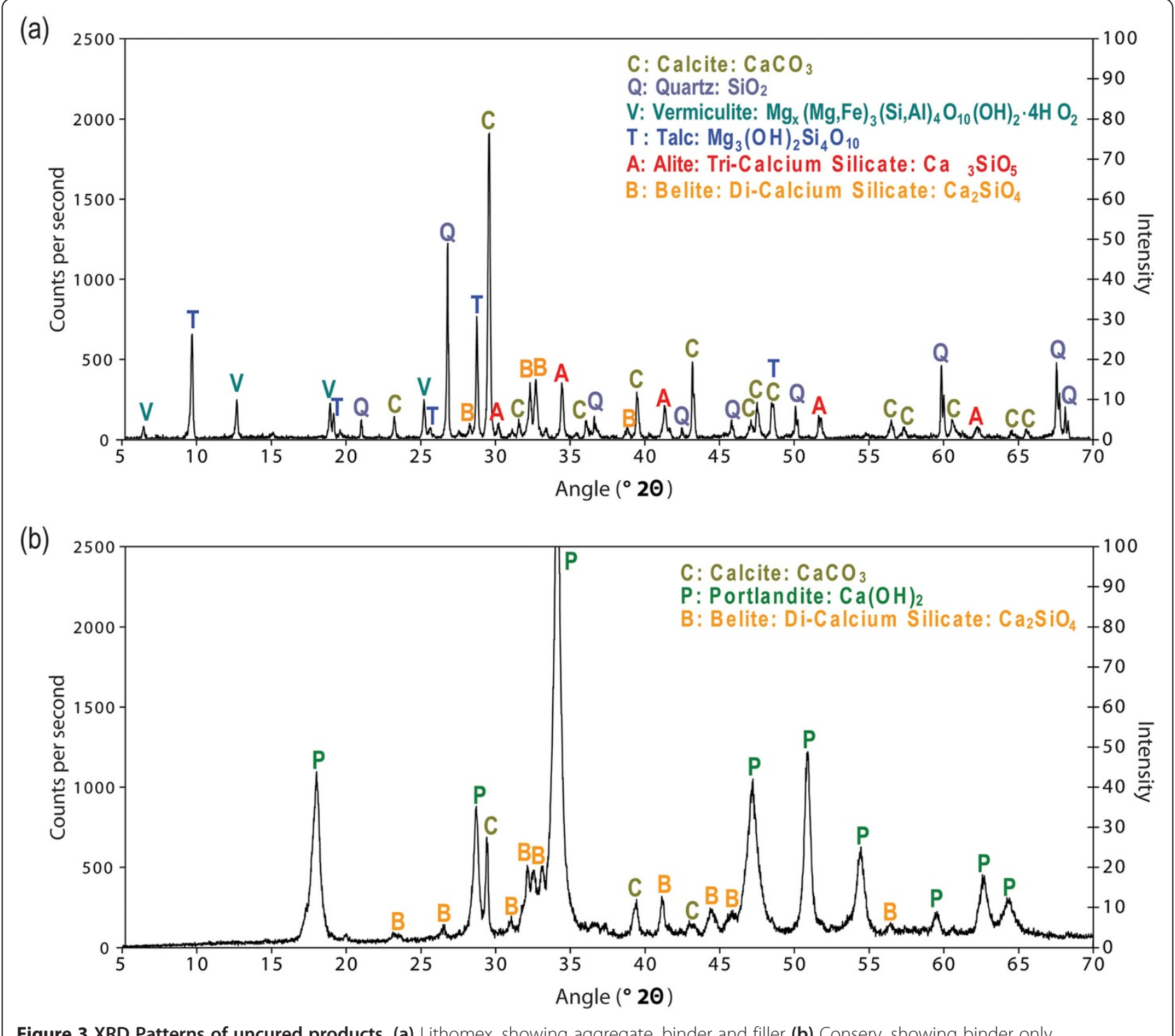

Figure 3 XRD Patterns of uncured products. (a) Lithomex, showing aggregate, binder and filler (b) Conserv, showing binder only.

the reduction in C-S-H formation as the rate of alite hydration diminishes, prior to the slow cumulative effects of $\beta$-belite hydration.

Conserv samples exhibited a much slower, yet steady gain in compressive strength up to 56 days (Table 2). Early strength gain (7 days) in Conserv is primarily the result of hardening during drying, as carbonation is negligible at this stage and there are no rapidly reacting hydraulic components present. Carbonation influences strength after this point. Later stage strength (after 56 days) in hydraulic limes is primarily attributable to the formation of C-S-H from hydration of $\beta$-belite [36], a reaction that continues at a steady rate for at least one year [47]. However, Conserv samples displayed a reduction in strength between 56 and 91 days possibly due to the pore structure changes associated with increasing carbonation [48]. Subsequent strength gain between 91 and 182 days may represent the hydration of $\beta$-belite after establishment of the pore structure. Both Lithomex and Conserv stone repair materials fall well below the compressive strength values of the natural sandstones (Table 2).

\section{Sorptivity}

Significant differences in sorptivity were observed between the two restoration mortars tested (Figure 5). Throughout the test period, Conserv had a sorptivity of at least 15 times greater than that of Lithomex, possibly due to the presence of Portland cement and/or organic additives in the latter.

Lithomex displays an initial decline in sorptivity from seven to 28 days, followed by a minor increase across the remainder of the test period. Given the very low sorptivity of the material, it is possible that these disparities simply 


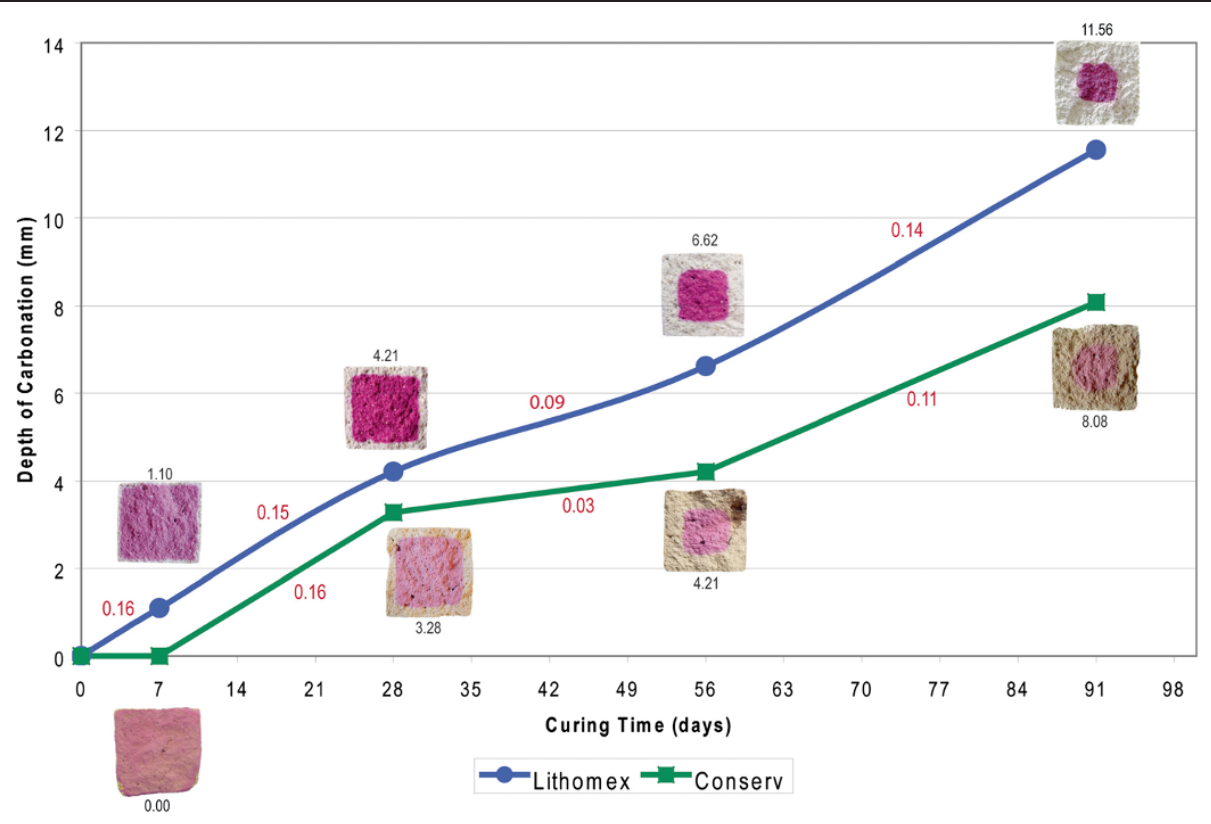

Figure 4 Carbonation rates of restoration mortars. Carbonation depth was determined by application of Phenolphthalein indicator; dark areas represent uncarbonated material. Numbers below the inset images indicate the average depth of carbonation (in mm). Numbers on the line graph indicate the rate of carbonation (in $\mathrm{mm} /$ day) between each testing phase.

represent variations in the surface pores of the samples tested, rather than any changes in the properties of the material itself. Observations of mortars on site have shown that there is little colour change in Lithomex repairs from dry to wet weather, compared with some stone types, which is likely to be a direct result of the materials' low sorptivity.

Conserv displays a much more complex evolution in sorptivity. The sorptivity of samples are expected to change in line with the microstructural changes that occur within the mortars during hydration and carbonation. The initial increase in sorptivity of Conserv, from seven to 28 days, may be attributable to an increase in pore volume associated with carbonation [48]. The subsequent decline from 28 days onwards will reflect the formation of C-S-H from $\beta$-belite and the coupled densification of the matrix, which leads to a reduction in the samples' permeability $[36,49]$.

There is variation in the sorptivity of the sandstone samples tested, undoubtedly linked to their textural and microstructure properties. Stanton Moor sandstone, which is fine to medium grained with an open porosity of $13.71 \%$ [39], has a lower sorptivity than Locharbriggs, a medium grained stone with $19.02 \%$ open porosity [40]. Lithomex sorptivity falls below both sandstones while Conserv is significantly higher.

\section{Water vapour permeability}

Rather than absolute values of vapour permeability, what is of greatest importance is the comparison of the restoration mortars with other materials, specifically those with which they may be used in conjunction with, i.e. substrates and adjacent building materials. Permeance values (Figure 6) suggest that it is unlikely that either of the restoration mortars would promote any significant vapour phase moisture build-up at the stone/repair interface when used in conjunction Stanton Moor sandstone, as this is less vapour permeable. It is unclear if a similar level of compatibility would be evident with Locharbriggs sandstone, due to

Table 2 Compressive strength of restoration mortars and stone

\begin{tabular}{llllll}
\hline & \multicolumn{4}{c}{ Compressive strength (MPa) } \\
\cline { 2 - 5 } & $\mathbf{7}$ days & $\mathbf{2 8}$ days & $\mathbf{5 6}$ days & $\mathbf{9 1}$ days & $\mathbf{1 8 2}$ days \\
\hline Lithomex & $6.40(0.96)$ & $7.92(0.10)$ & $7.67(0.54)$ & $8.32(0.70)$ & $9.19(1.11)$ \\
Conserv & $0.47(0.20)$ & $1.09(0.14)$ & $1.36(0.22)$ & $0.97(0.15)$ & $1.01(0.14)$ \\
Stanton Moor Sandstone & $71.66^{*}$ & & & \\
Locharbriggs Sandstone & $54.45^{*}$ & & & \\
\hline
\end{tabular}

Values for restoration mortars are given at different curing times; values in brackets indicate standard deviation. ${ }^{*}$ denotes manufacturer's data (Stancliffe Stone, $2010 a ; 2010 b)[39,40]$. 


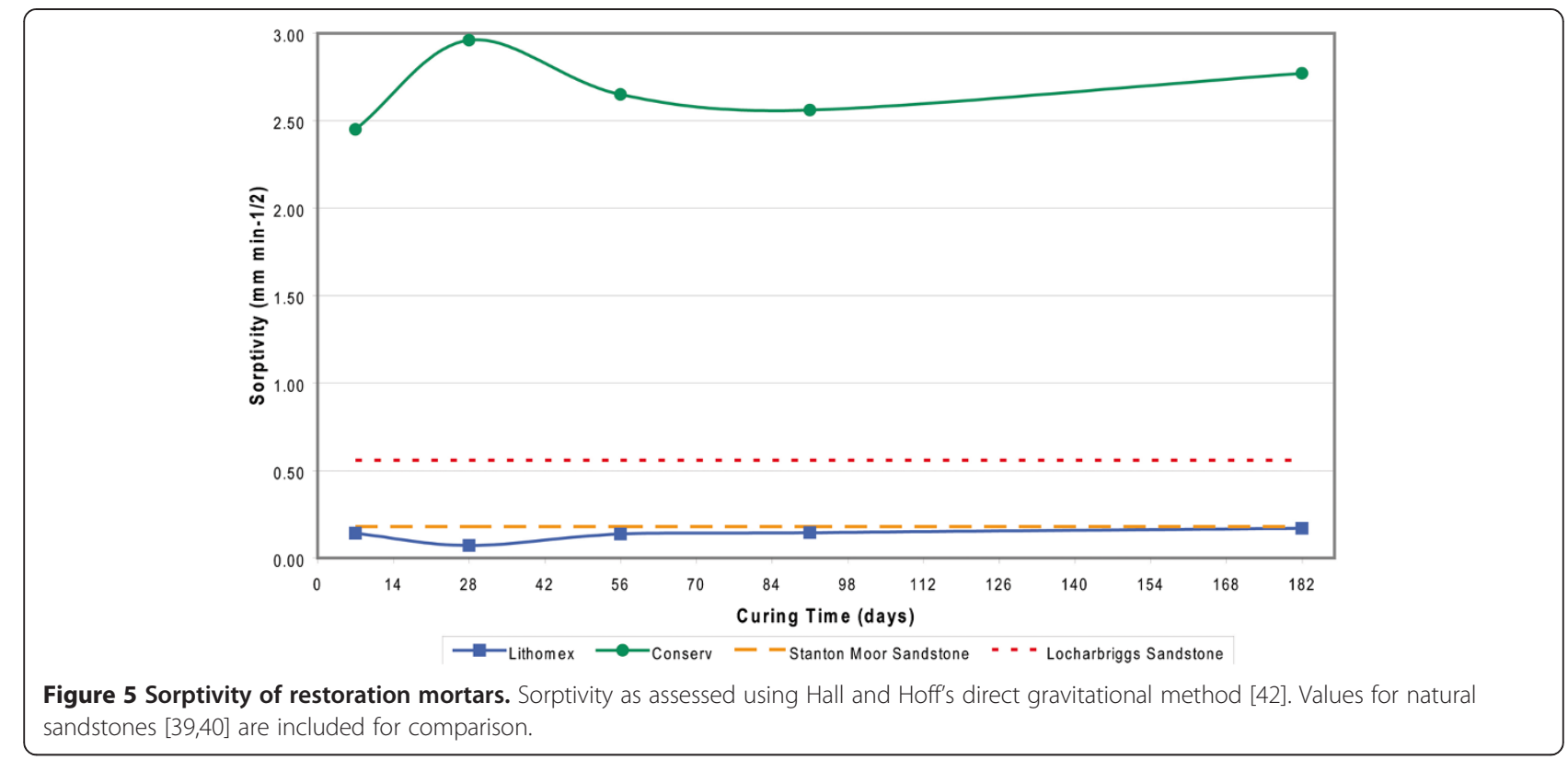

its higher vapour permeance relative to the restoration mortars. Testing of a wider range of materials may give an indication of whether minor variations in permeance are likely to negatively impact upon materials compatibility.

\section{Conclusions}

Lithomex and Conserv stone repair mortars, essentially designed and manufactured for the same purpose, have significantly different physical properties. These differences are primarily associated with variations in the chemical composition of the material. Lithomex is significantly stronger than Conserv, due in part to its $20 \%$ cement component. This has a strong influence on the microstructural and mechanical strength development during setting and hardening. This is also potentially responsible for its lower sorptivity. Despite these properties, Lithomex is considered to retain a good degree of vapour permeability, falling within the same range as the sandstones tested. Comparison with these natural sandstones shows that although both repair materials are significantly weaker than stone, the water transmission properties can fall at either higher or lower values. These results highlight the need for the end-user to have an in-depth understanding of the materials they are procuring. It cannot be assumed that one restoration mortar will behave in the same, or even similar manner to another.

The contradictory high vapour permeability and low sorptivity of Lithomex, presumably attained using specific additives, highlights the need for a sound understanding of substrate material. Although transmission of vapour phase moisture may be unlikely to be seriously hindered by the use of Lithomex with substrates of similar or lower

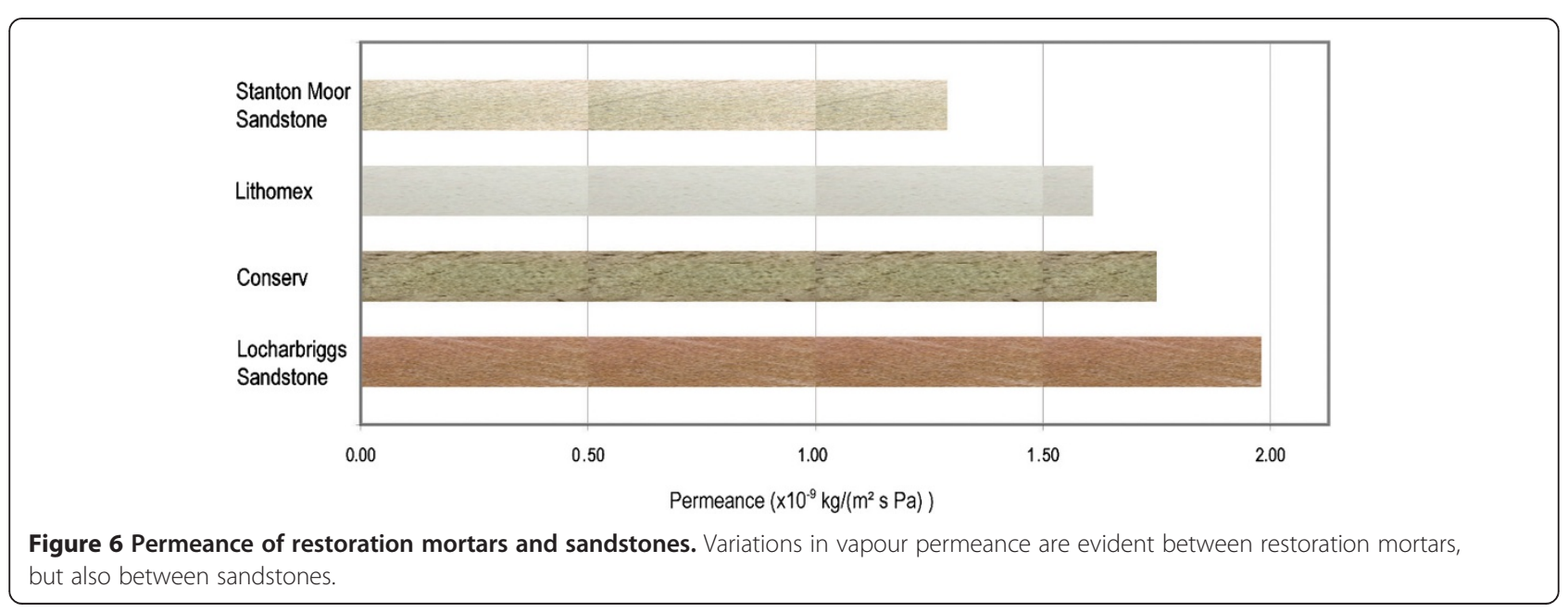


vapour permeability, it is unclear how the material's very low sorptivity might impact upon liquid phase moisture loss from very wet/saturated masonry in which water does not enter the vapour phase. Any impedance in the diffusion of liquid water and evaporation of water vapour through a restoration mortar could prove detrimental to the built heritage. The widespread use of these products [2] clearly raises concerns for issues of medium and long term latent building defects and their associated deteriorogical mechanisms.

The considerable difference in properties of Conserv and Lithomex restoration mortars raise the question of whether stone repair materials should be more carefully selected. The results presented here highlight the importance of using a specification framework, similar to those for building limes [50], for stone repair materials. This would obviate the simple assumption of suitability of a restoration mortar for use on numerous substrate types [15-17,50]. The importance attached to the evaluation of substrate properties concurs with previous studies undertaken by various researchers [15-17]. These results emphasize the need for a thorough understanding of material properties and site conditions in order to provide an understanding of how repair materials will perform. This must be viewed in conjunction with an appreciation of appropriate specification criteria for conservation work. Further research into the microstructural properties of these materials may give additional insights into the causes of their different physical properties. This should be combined with on-site observation and testing to identify any potentially problematic macro-scale issues associated with restoration mortars, particularly in relation to moisture transmission and retention. Understanding these factors amongst others, are essential to prevent damage to the built heritage through the use of incompatible repair materials.

\section{Competing interests}

The authors declare that they have no competing interests.

\section{Authors' contributions}

$C T$ conceived and coordinated the research, manufactured samples, acquired, evaluated and interpreted data and drafted the manuscript. AMF evaluated and interpreted data and drafted the manuscript. EMS manufactured samples and acquired, evaluated and interpreted data. All authors read and approved the final manuscript.

\section{Acknowledgements}

The authors thank Stancliffe Stone for providing the sandstone samples that were analysed. Mr Alastair MacFarlane and Mr Graham Sorley (Heriot-Watt University) are thanked for their technical support throughout this study. Prof Phil Banfill, Mr Bill Revie and Dr Craig Kennedy are acknowledged for providing comments on an earlier draft of this paper.

\section{Author details}

'Historic Scotland Conservation Directorate, 7 South Gyle Crescent, Edinburgh, UK. ${ }^{2}$ School of the Built Environment, Heriot-Watt University, Edinburgh, UK.
Received: 17 June 2013 Accepted: 13 November 2013

Published: 1 January 2014

\section{References}

1. Forster AM, Carter K, Banfill PFG, Kayan B: Green maintenance for historic masonry buildings: an emerging concept. Build Res Inform 2011, 39(6):656-664.

2. Torney C, Forster AM, Kennedy CJ, Hyslop EK: Plastic' Repair of natural stone in Scotland: perceptions and practice. Struct Surv 2012, 30:297-311.

3. Ashurst J, Ashurst N: Practical building conservation: stone masonry: english heritage technical handbook volume 1. Avon: Gower Technical Press; 1988.

4. Forster AM: Building conservation philosophy for masonry repair: part 2 'principles. Struct Surv: J Build Pathol Refurbish 2010, 28(3):165-188.

5. Odgers D, Henry A: English heritage practical building conservation stone. Farnham: Ashgate Publishing Limited; 2012.

6. Knight J: The repair of historic buildings in Scotland; advice on the principles and methods. Edinburgh: Historic Scotland; 1995.

7. Gibbons P: The preparation and use of lime mortars: technical advice note 1 . Edinburgh: Historic Scotland; 2003.

8. Hughes P: The need for old buildings to breathe: information sheet 4. London: Society for the Protection of Ancient Buildings; 1986.

9. Webster R: Stone cleaning and the nature, soiling and decay mechanisms of stone. London: Donhead; 1992.

10. Young D: Salt attack and rising damp. A guide to salt damp in historic and older buildings. Technical guide. Heritage council of NSW. http://www. adelaidecitycouncil.com/assets/acc/Development/heritage/docs/ salt_attack_rising_damp_technical_guide.pdf.

11. Henry A, Stewart J: English heritage practical building conservation mortars, renders and plasters. Farnham: Ashgate Publishing Limited; 2011.

12. Murphy JM, Sexton DMH, Jenkins GJ, Boorman PM, Booth BBB, Brown CC, Clark RT, Collins M, Harris GR, Kendon El, Betts RA, Brown SJ, Howard TP, Humphrey KA, McCarthy MP, McDonald RE, Stephens A, Wallace C, Warren R, Wilby R, Wood RA: UK climate change projections science report: climate change projections: technical report. Exeter: Meteorological Office Hadley Centre; 2009. http://scdc. onesuffolk.net/assets/Documents/LDF/B7f/UKCP09ProjectionsV2.pdf.

13. Taylor HFW: Cement chemistry. London: Academic; 1990.

14. Williams G: Repointing stone and brick walling: technical pamphlet 5. London: Society for the Protection of Ancient Buildings; 2001.

15. Mikos $E$, Schubert $P$, Knöfel $D$ : Zur beurteilung von steinergänzungsstoffen für die restaurierung von natursteinoberflächen. Bautenschutz Bausanierung 1992, 15(4):34-40.

16. Rodrigues DJ, Grossi A: Indicators and ratings for the compatibility assessment of conservation actions. J Cult Heritage 2007, 8:32-43.

17. Schueremans L, Cizer O, Janssens E, Serre G, Van Balen K: Characterization of repair mortars for the assessment of their compatibility in restoration projects: research and practice. Construct Build Mater 2011, 25:4338-4350.

18. Allen G, Allen J, Elton N, Farey N, Holmes S, Livesey P, Radonjic M: Hydraulic lime mortar for stone, brick and block masonry. Dorset: Donhead; 2003.

19. Groot C: RILEM TC 203-RHM: repair mortars for historic masonry. Performance requirements for renders and plasters. Mat Struct 2012, 45:1277-1285.

20. Hughes JJ: RILEM TC 203-RHM: repair mortars for historic masonry. The role of mortar in masonry: an introduction to requirements for the design of repair mortars. Mat Struct 2012, 45:1287-1294.

21. Van Hees R: RILEM TC 203-RHM: repair mortars for historic masonry. Repair mortars for historic masonry. From problem to intervention: a decision process. Mat Struct 2012, 45:1295-1302.

22. Maurenbrecher P: RILEM TC 203-RHM: repair mortars for historic masonry. Requirements for repointing mortars for historic masonry. Mat Struct 2012, 45:1303-1309.

23. Forster AM: The relationship between water vapour permeability and hydraulicity in hydraulic lime mortars with particular reference to building conservation materials science. Edinburgh: Heriot Watt University; 2002.

24. British Standards Institution: BS 8221-2:2000. Code of practise for cleaning and surface repair of buildings - surface repair of natural stones, brick and terracotta. London: BSI; 2000 .

25. Glasgow Conservation Trust: Glasgow west conservation manual: stone conservation. Glasgow: Glasgow Conservation Trust; 1996.

26. Historic Scotland: Building repair grants scheme, advisory standards of repair: revision C. http://www.historic-scotland.gov.uk/index/heritage/grants/ building-repair-grants.htm. 
27. Moreno F, Vilela SAG, Antunes ASG, Alves CAS: Capillary-rising salt pollution and granitic stone erosive decay in the parish church of Torre de Moncorvo (NE Portugal)-implications for conservation strategy. J Cult Heritage 2006, 7:56-66.

28. Friolo KH, Stuart B, Ray A: Characterisation of weathering of Sydney sandstones in heritage buildings. J Cult Heritage 2003, 4:211-220.

29. New York Landmarks Conservancy: The brownstone guide: maintenance \& repair facts for historic property owners. New York: New York Landmarks Conservancy; 2003.

30. Szemerey-Kiss B, Török Á: Time-dependant changes in the strength of repair mortar used in the loss compensation of stone. Environ Earth Sci 2010, 63:1613-1621.

31. Gulotta D, Goidanich S, Tedeschi C, Nijland TG, Toniolo L: Commercial $\mathrm{NHL}$-containing mortars for the preservation of historical architecture. Part 1: compositional and mechanical characterisation. Construct Build Mater 2013, 38:31-42. Edited By Andrew J. Boyd and Aldo De La Haza.

32. Hyslop EK, McMillan AA, Maxwell I: Stone in Scotland. Paris: UNESCO Publishing; 2006

33. Building Research Establishment: BRE stone list. http://projects.bre.co.uk/ stonelist/.

34. Setra Marketing Ltd: Health and safety recommendations for lithomex from St. Astier. http://www.stastier.co.uk/lithomex/lithomex-hs.php.

35. Setra Marketing Ltd: Stone repair mortar - lithomex from St. Astier. Plastic repair materials for natural stone and masonry. http://www.stastier.co.uk/ lithomex/stonerepair.php.

36. Forster AM: How hydraulic lime binders work. Hydraulicity for beginners and the hydraulic lime family. Edinburgh: Love Your Building Publishing; 2004.

37. British Standards Institution: BS EN 1015-3:1999. Methods of test for mortar for masonry. Determination of consistence of fresh mortar (by flow table). London: BSI; 1999.

38. Frew C: Pointing with lime. In The building conservation directory. Edited by Taylor J. Tisbury: Cathedral Communications Limited; 2007.

39. Stancliffe Stone: Stanton moor buff sandstone data sheet. http://www. stancliffe.com/Content/Productlnformation/PDFs/StoneTypes/StancliffeStone-Stanton-Moor-Buff-Sandstone.pdf.

40. Stancliffe Stone: Locharbriggs sandstone data shee. http://www.stancliffe. com/Content/ProductInformation/PDFs/StoneTypes/Stancliffe-StoneLocharbriggs-Red-Sandstone.pdf.

41. British Standards Institution: BS EN 13139:2002. Aggregates for mortar. London: BSI; 2002.

42. Hall C, Hoff WD: Water transport in brick, stone and concrete. London: Taylor \& Francis; 2012.

43. British Standards Institution: BS EN 15801:2008. Conservation of cultural property. Test methods. Determination of water absorption by capillarity. London: BSI; 2008.

44. British Standards Institution: BS EN 1015-19:1999. Methods of test for mortar for masonry - determination of water vapour permeability of hardened rendering and plastering mortars. London: BSI; 1999.

45. Read HH: Rutley's elements of mineralogy. 26th edition. London: Thomas Murby and Co; 1970

46. Neville AM, Brooks Jj: Concrete technology. Harlow: Longman Scientific and Technical; 1994.

47. Hewlett PC: Lea's chemistry of cement and concrete. 4th edition. Oxford: Butterworth-Heinemann; 2004.

48. Lawrence RM, Mays TJ, Rigby SP, Walker P, D'Ayala D: Effects of carbonation on the pore structure of non-hydraulic lime mortars. Cement Concrete Res 2007, 37:1059-1069.

49. Banfill PFG, Forster AM: A relationship between hydraulicity and permeability of hydraulic lime. In Historic mortars: characteristics and tests, proceedings of the international RILEM workshop (PRO 12). Edited by Bartos P, Groot C, Hughes JJ. France: RILEM Publications S. A. R. L; 1999.

50. Forster AM, Carter K: A framework for specifying natural hydraulic lime mortars for masonry construction. Struct Surv 2011, 29:373-396.

doi:10.1186/2050-7445-2-1

Cite this article as: Torney et al:: Specialist 'restoration mortars' for stone elements: a comparison of the physical properties of two stone repair materials. Heritage Science 2014 2:1.

\section{Publish with ChemistryCentral and every scientist can read your work free of charge \\ "Open access provides opportunities to our colleagues in other parts of the globe, by allowing anyone to view the content free of charge." W. Jeffery Hurst, The Hershey Company. \\ - available free of charge to the entire scientific community \\ - peer reviewed and published immediately upon acceptance \\ - cited in PubMed and archived on PubMed Central \\ - yours - you keep the copyright \\ Submit your manuscript here: \\ http://www.chemistrycentral.com/manuscript/<smiles>c1ccccc1</smiles> \\ Chemistry Central}

